\title{
Deep Brain Stimulation Reduces Tic-Related Neural Activity via Temporal Locking with Stimulus Pulses
}

\author{
Kevin W. McCairn, ${ }^{1,2}$ Atsushi Iriki, ${ }^{2}$ and Masaki Isoda ${ }^{1,2}$ \\ ${ }^{1}$ Unit on Neural Systems and Behavior, Okinawa Institute of Science and Technology, Onna-son, Okinawa 904-0495, Japan, and ${ }^{2}$ Laboratory for Symbolic \\ Cognitive Development, RIKEN Brain Science Institute, Wako, Saitama 351-0198, Japan
}

\begin{abstract}
A neurosurgical intervention that has shown potential for treating basal ganglia (BG) mediated motor tics involves high-frequency deep brain stimulation (HF-DBS) targeted to the output nucleus of the BG: the globus pallidus internus (GPi). This study used a nonhuman primate (Macaca fuscata) model of BG-meditated motor tics, and investigated the short-term neuronal mechanism that might underlie the beneficial effects of GPi-HF-DBS. In parallel with behavioral tic expressions, phasic alterations of neuronal activity emerged in the pallidum following focal disinhibition of the striatum with bicuculline. We delivered HF-DBS in the GPi in such a way that on-stimulation and off-stimulation conditions alternated every $30 \mathrm{~s}$. Analysis of electromyographic (EMG) records showed that during on-stimulation, there were significant reductions in tic-related EMG amplitude. Analysis of pallidal activity showed that GPi-HF-DBS induced both sustained and transient patterns of excitation and inhibition in both segments of the GP. Population-scale firing rates were initially raised relative to baseline, but were not significantly different by the time stimulation ceased. Modulation of behavior and neuronal firing rates were associated with the reduction of tic-related phasic activity in pallidal cells. Examination of short-latency responses showed that firing rate changes were strongly associated with locking of the cells' activity with the HF-DBS pulse. This temporal locking often induced multiphasic changes of firing rates in individual cells, which dynamically changed across the stimulation period. These results support clinical studies that reported success in treating motor tics with GPi-HF-DBS, and demonstrate that the underlying local mechanism within the GP is suppression of tic-related activity through temporal locking with the stimulation pulse.
\end{abstract}

\section{Introduction}

High-frequency deep brain stimulation (HF-DBS) has emerged as the predominant neurosurgical treatment for basal ganglia (BG) mediated movement disorders. Typically, the therapy is used for conditions, such as Parkinson's disease and dystonia (Krauss et al., 1999; Starr et al., 2004; Rodriguez-Oroz et al., 2005; Bronstein et al., 2011), yet recently it has also been tried experimentally for treating BG-mediated hyperkinetic motor disorders, such as motor tics and Tourette syndrome (TS) (Vandewalle et al., 1999; van der Linden et al., 2002; Houeto et al., 2005; Shahed et al., 2007; Dehning et al., 2008; Dueck et al., 2009; MartinezTorres et al., 2009; Welter et al., 2010; Azoulay-Zyss et al., 2011; Martinez-Fernandez et al., 2011; Piedimonte et al., 2012). The

Received 0ct. 16, 2012; revised Feb. 13, 2013; accepted Feb. 23, 2013.

Author contributions: K.W.M., A.I., and M.I. designed research; K.W.M. and M.I. performed research; K.W.M. and M.I. analyzed data; K.W.M., A.I., and M.I. wrote the paper.

We thank Drs. Y. Imamura, Y. Tsunoda, and K. Yoshida for technical assistance. The monkeys used in this research were provided by the National BioResource Project "Japanese Monkeys" of the Ministry of Education, Culture, Sports, Science, and Technology, Japan.

The authors declare no competing financial interests.

This article is freely available online through the J Neurosci Author Open Choice option.

Correspondence should be addressed to Dr. Kevin W. McCairn, Kyoto University Primate Research I, Inuyama, Aichi 484-8506, Japan. E-mail: kevin.mccairn@yahoo.com.

K.W. McCairn's present address: System Neuroscience Section, Primate Research Institute, Kyoto University, Inuyama, Aichi 484-8506, Japan.

M. Isoda's present address: Department of Physiology, Kansai Medical University School of Medicine, Moriguchi, Osaka 570-8506, Japan.

DOI:10.1523/JNEUROSCI.4874-12.2013

Copyright $\odot 2013$ the authors $\quad 0270-6474 / 13 / 336581-13 \$ 15.00 / 0$ emerging clinical data with respect to HF-DBS for TS is also supported by positive responses to stimulation in animal models of tourettism (Baup et al., 2008; McCairn et al., 2012). However, the underlying mechanisms of action of HF-DBS remain elusive for TS.

It has been generally agreed that the tics in TS are associated with basal ganglia abnormalities (Mink, 2001; Peterson, 2001; Albin and Mink, 2006) and can result from dysfunctional GABAergic networks (Kalanithi et al., 2005; Kataoka et al., 2010; Lerner et al., 2012). Recent studies in nonhuman primates (NHPs) have shown that during the expression of BG-mediated tics, widespread, phasic alterations in neuronal activity occur in the external and internal segments of globus pallidus (GPe and GPi, respectively) (McCairn et al., 2009, 2012, 2013; Bronfeld et al., 2011). The localization of pathological activity to the output nucleus of the basal ganglia provides a convenient target for neurosurgical intervention.

With HF-DBS being an experimental treatment for TS, there is still vigorous debate with respect to the optimal site for placement of DBS electrodes. Current claims from various centers suggest that both segments of the pallidum (van der Linden et al., 2002; Piedimonte et al., 2012), the subthalamic nucleus (STN) (Martinez-Torres et al., 2009), and the thalamus (Vandewalle et al., 1999) are all potential sites for therapeutic stimulation, for review see Ackermans et al. (2012).

The aim of the present study was threefold: (1) to determine whether and to what extent GPi-HF-DBS can ameliorate BGmediated motor tics (2) to assess the neuronal correlates of motor 
tics in the pallidum, and (3) to clarify how pallidal activity responds to HF-DBS. Here, we performed extracellular microelectrode recording in the GPe and GPi while simultaneously delivering HF-DBS to the GPi using a validated stimulus artifact rejection paradigm (McCairn and Turner, 2009; McCairn et al., 2012). We generated a reversible, pharmacologic model of motor tics in monkeys by microinjecting the GABA antagonist bicuculline into the sensorimotor striatum (putamen) as previously reported (McCairn et al., 2009, 2012, 2013). Our experimental setup allowed not only for testing the behavioral and pallidal responses to motor tics, but also for examining neuronal and behavioral changes during delivery of GPi-HF-DBS.

\section{Materials and Methods}

Animals. Two macaque monkeys (Monkey "R" and Monkey "B"; Macaca fuscata, male; weight 6-7 kg) were used in this study. The animals' health was monitored by a veterinarian and their fluid consumption, diet, and weight were monitored daily. All procedures were in accordance with the National Institutes of Health Guide for the Care and Use of Laboratory Animals (1996) and were approved by the RIKEN Animal Experiment Committee.

Surgical procedure. The surgical procedures for cranial implantation were conducted under aseptic conditions using pentobarbital anesthesia (30 mg/kg, i.v.), after induction with ketamine $\mathrm{HCl}$ (10 mg/kg, i.m.). Cranial implantation used one square polyetherimide chamber (27 $\mathrm{mm} \times 27 \mathrm{~mm}$ ) (Alpha-Omega Engineering), which was implanted stereotaxically to allow access to the basal ganglia using a coronal approach in the left hemisphere. The recording chamber was tilted at $30^{\circ}$ in the coronal plane, with the center targeted to the middle of the globus pallidus (GP): stereotactic coordinates A21, L7, and H15 (Kusama and Mabuchi, 1970). The chambers were fixed into place using bone screws and methyl-methacrylate cement. In addition, a head-holder connector and an electroencephalogram (EEG) screw (Crist Instrument) were attached to the skull. Prophylactic antibiotics and analgesics were administered postsurgically.

Experimental setup. The animals were trained to sit in a primate chair (Crist Instrument) and were allowed to complete a simple sensorimotor task (visually guided button pressing) for delivery of a liquid reward. The inclusion of the task was necessary to occupy the animal and maintain a calm state during recording sessions; however, it should be noted that the animals were free to not engage the task as it had no bearing on the experimental outcomes. Spontaneous behaviors and task execution were observed and recorded during each experimental session using a multichannel video system (GV-800, Geovision). Digital images from each of the separate cameras were captured at 25 frames per second and stored on a hard disk for off-line analysis. The system was designed to visualize behavioral sequences from four different locations: face, upper limbs, lower limbs, and the behavioral task. In addition, electromyography (EMG) signals were sampled from four muscles: biceps, triceps, zygomaticus major, and ventral orbicularis oris. EMG wires were constructed from $100 \mu \mathrm{m}$ Teflon-coated silver (A-M Systems). The EMG wires were percutaneous and inserted just before each experimental session using a 27 gauge hypodermic needle. EMG signals were sampled at $5 \mathrm{kHz}$ and bandpass filtered (5-450 Hz, 4 pole Butterworth filter).

Electrophysiological recording. After recovery from surgery, the animals underwent microelectrode-guided mapping of the striatum, GPe, and GPi. The striatum and the GP were identified by their characteristic neuronal activity and their relation to known anatomical boundaries, as previously described (McCairn et al., 2009, 2012, 2013), under the guidance of a standard stereotaxic atlas (Kusama and Mabuchi, 1970). The identification of the divisions of the pallidum (GPe vs GPi) was possible through their distinct firing patterns; the GPe has a high-frequency discharge, although slightly slower than the GPi, and shows distinct pauses, whereas the GPi expresses a higher frequency tonic activity with no pauses when the animal is at rest (DeLong, 1971, 1972). The preliminary mapping process was followed by experimental sessions. During each session, up to 8 glass-coated tungsten microelectrodes (impedance, 250$750 \mathrm{~K} \Omega$ at $1 \mathrm{kHz}$ ) and an injectrode (28 gauge cannula surrounding a parylene-coated $50 \mu \mathrm{m}$ microelectrode extending $0.5 \mathrm{~mm}$ beyond the tip of the injection cannula (Alpha Omega Engineering) were introduced using two separate manipulating towers that could move each electrode independently with $2 \mu \mathrm{m}$ resolution (DMT and EPS, Alpha-Omega Engineering). The microinjection cannula was connected via a Delrin manifold to a $10 \mu \mathrm{l}$ syringe (Hamilton Company) filled with bicuculline (Sigma-Aldrich). The depth of the injection site within the striatum was determined by electrophysiological recording using the injectrode. All electrophysiological data were passed through a low-gain 16-channel headstage (2-7.5 kHz bandpass) and then digitized at $24 \mathrm{kHz}$ (16-bit resolution, Tucker Davis Technologies). The digitized signals were filtered $(300 \mathrm{~Hz}-6 \mathrm{kHz}$; first-order Butterworth) and saved to a disk either as continuous data or as 38-sample-long snippets of the continuous data stream. After a sufficient numbers of separable neurons had been identified on the electrodes, and were stable for a minimum of $1 \mathrm{~min}$, bicuculline (Sigma-Aldrich) dissolved in physiological saline $(15 \mu \mathrm{g} / \mu \mathrm{l})$ was slowly injected $(1.0-2.0 \mu \mathrm{l})$ at a rate of $\sim 2 \mu \mathrm{l} / \mathrm{min}$. If the effects of bicuculline were diminishing, which typically occurred $60 \mathrm{~min}$ after the first injection, additional injections were administered up to a maximum of $8 \mu \mathrm{l}$ to maximize the number of cells recorded in each session. This methodological constraint precluded the investigation of whether GPiHF-DBS altered the total length of the tic state.

In addition, on each experimental day a dual contact DBS probe (surface areas $\sim 0.5 \mathrm{~mm}^{2} /$ contact, impedance $<1 \mathrm{k} \Omega$ at $1 \mathrm{kHz}$; Unique Medical) was lowered into the GPi using the same manipulating towers to allow for the macrostimulation of the target area. The stimulating electrode remained in place for the duration of the experiment and was removed after each experimental day. The exact stimulation site was determined from previous electrophysiological mapping and on each experimental day by recordings from electrodes that surrounded the stimulation electrode; these electrodes were useful for identifying anatomical boundaries along the recording trajectory and the distinct firing patterns of GPi neurons. When an effective site that induced a therapeutic response was identified, subsequent experimental days targeted the same position. Stimulation was delivered to the GPi using an isolated stimulator (Model IZ-32, TDT). The parameters of stimulation consisted of symmetric biphasic pulses (cathodal followed by anodal) of $60 \mu \mathrm{s}$ duration at $150 \mathrm{~Hz}$ with an intensity of $1 \mathrm{~V}$ for blocks of $30 \mathrm{~s}$. Neuronal data were then collected during an initial $1 \mathrm{~min}$ off-stimulation period ("baseline" or "control"), followed by 30 s blocks of stimulation delivered once every $60 \mathrm{~s}$. Cells were only considered for off-line analysis if at least three $30 \mathrm{~s}$ blocks of stimulation were obtained with their corresponding control periods. Stimulation artifacts were removed on-line using a template subtraction method, with further off-line processing using custom MATLAB scripts (V2007B, Mathworks) (McCairn and Turner, 2009; McCairn et al., 2012) (Fig. 1A).

Off-line analysis of neuronal activity. The action potentials of individual neurons were sorted off-line by drawing contours around waveform clusters in principal components space (Offline Sorter, Plexon). Neurons were accepted for further analysis if they met the following criteria: (1) the recording was from a location within the GP; (2) the unit's action potentials were of a consistent distinct shape that could be separated with a high degree of certainty from the spike waveforms of other neurons and background noise; (3) the unit's interspike intervals were confirmed to have a minimum refractory period of $1.5 \mathrm{~ms}$; and (4) there was no evidence that unit isolation was compromised by shock artifacts.

To test for stimulation-induced corruption of sorted spike waveforms, a $95 \%$ confidence interval was computed for the mean shape of a neuron's action potentials during all nonstimulation control periods. This control mean was then compared with acquired action potentials during the stimulation period, which were divided into four nonoverlapping bins of $1.67 \mathrm{~ms}$ (Fig. 1B). A neuron was rejected if the mean waveform shape exceeded the confidence interval calculated from the control periods. To allow for long-lasting changes in waveform profiles induced by stimulation, two exceptions were applied to the quality control rule. One was when spike waveforms were altered uniformly across the four interstimulus intervals. This exception allowed the inclusion of neurons that showed long-lasting stimulation-induced changes in action potential size, similar to those reported previously (Hashimoto et al., 2003; Mc- 
A

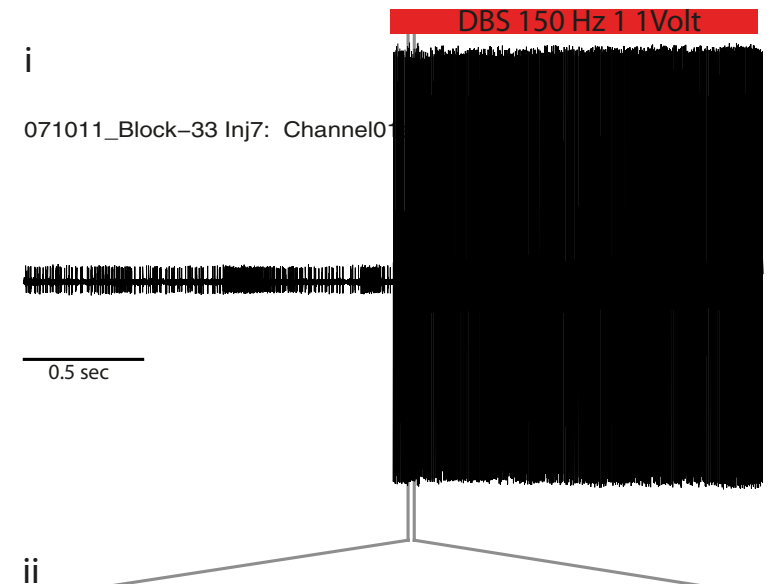

ii
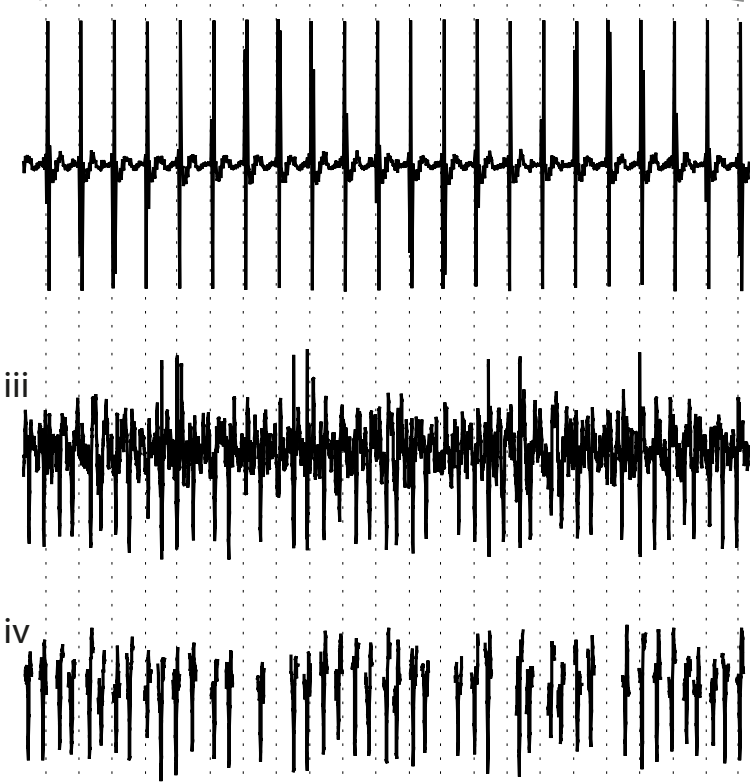

$\overline{10 \mathrm{~ms}}$

B

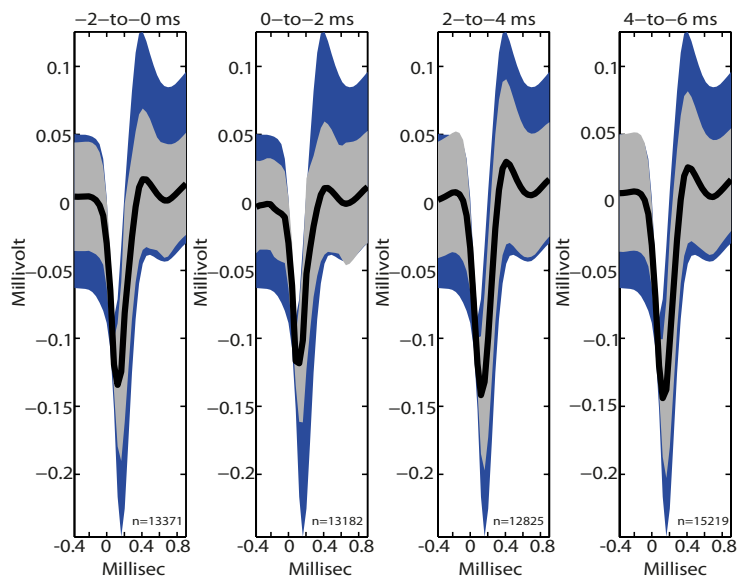

Figure 1. Validation of artifact subtraction method. Ai, A neuronal signal acquired just before and during GPi-HF-DBS but with artifact subtraction disabled, note the presence of large voltage transients as DBS starts. Aii, Higher magnification of the period during which DBS was activated showing the large voltage transients which occurred time locked to the delivery of the stimulation pulse (vertical dashed lines; $150 \mathrm{~Hz}, 1 \mathrm{~V}, 60 \mu$ s pulsewidth). Aiii, The same microelectrode signal acquired on a parallel acquisition channel with artifact subtraction working shows no evidence of shock artifacts while action potentials and recording noise are preserved. Action potentials that were completely obscured by artifacts in the unsubtracted data stream
Cairn and Turner, 2009). The second exception was when an inhibitory effect of GPi-HF-DBS was so profound as to prevent the occurrence of all spiking activity during one or more peristimulus interval. Further details with respect to the quality control methods used for spike identification can be found in McCairn and Turner (2009).

Data analysis. Following off-line sorting of the neuronal data, the spike trains were correlated with behavioral events using a MATLAB (V2007B, Mathworks) and Neuroexplorer (V4, Nex Technologies) environment. The EMG signals were processed off-line and the envelope was estimated by rectifying the signal, followed by low-pass filtering $(10 \mathrm{~Hz}, 8$ pole Butterworth filter). Detection of tics used the rectified and filtered EMG signal via a threshold crossing method. Behavioral events were identified using frame-by-frame video analysis and aligned to EMG activity to exclude nonrelevant muscular activity, as previously described (McCairn et al., 2009, 2012). Significant differences between the two states, i.e., onstimulation and off-stimulation conditions, in the peak amplitude of the EMG were tested for by performing a $t$ test across the rectified, concatenated prestimulation and poststimulation matrices of EMG traces. This gave a $p$ value for each analyzed bin $(10 \mathrm{~ms})$ with a significance threshold of $p=0.001$ (see Fig. $3 B$, inset). The time stamps indicating the onset of tic-related EMG were then used to construct perievent histograms for neuronal data (using $10 \mathrm{~ms}$ bins).

The significance of neuronal activity in perievent histograms was analyzed by constructing $99 \%$ confidence limits on the basis of the mean and SD of neuronal activity within the tail of the histogram (activity at $2-0.2 \mathrm{~s}$ before the tic). A neuron was considered to have a significant perievent response when its activity crossed the assigned confidence level for three successive bins and the $\mathrm{z}$-score was $>3$. Significant cellular responses to HF-DBS used the same methodology. The histograms of neuronal activity between the two stimulation conditions were constructed and the presence or absence of tic-related activity was determined by $99 \%$ confidence threshold crossings. Population-scale statistical analysis of the amplitude of tic responses between the onstimulation and off-stimulation states used a paired $t$ test.

The primary tests for long-latency effects of DBS on a neuron's firing were performed on a peristimulus histogram (bin size $=0.2 \mathrm{~ms}$ ). Significant responses to HF-DBS were initially determined via $99 \%$ threshold crossings. To calculate population-scale mean firing rate changes during GPi-HF-DBS, the data were normalized by subtracting the mean of the $30 \mathrm{~s}$ of prestimulation data as a measure of neural activity around a baseline of zero. To assess the stability of any rate changes across the stimulation period, the peristimulus histogram was divided into 6 epochs covering the prestimulation and poststimulation period, each consisting of $10 \mathrm{~s}$. The data for each stimulation period (epoch 4-6) was compared with control periods (epoch 1-3) using multicomparison ANOVA with Tukey's HSD error correction.

Short-latency phasic responses $(0-6 \mathrm{~ms})$ were examined for changes in timing and magnitude across the $30 \mathrm{~s}$ blocks of stimulation using peristimulus histograms versus time analysis. Mean peristimulus histograms were computed (bin size $=4.1 \mathrm{e}-005 \mathrm{~ms}$, and shifted using a $0.25 \mathrm{~s}$ overlapping window, 120 bins) to give a matrix of neuronal activity, which showed evolving short latency responses across the entire stimulation block (see Fig. 7). Each block was summed and the mean from all the control periods was subtracted to give an estimate of rate change around a baseline of zero. The timing of maximal response peaks was determined in each histogram and changes in slope progression were calculated using piece-wise regression analysis.

Histology. After completion of the experiment, the animals were deeply anesthetized using ketamine $(10 \mathrm{mg} / \mathrm{kg})$ and sodium pentobarbi-

were easily detected in the processed data stream. Aiv, Showing action potential waveform snippets that have been processed using off-line sorting. $\boldsymbol{B}$, Off-line test of artifact subtraction efficacy. The mean waveforms of spikes during stimulation (thick black lines; \pm SEM indicated by gray shading) were required to fall within the $95 \%$ confidence interval for all spikes from nonstimulation periods (blue shading). The test was performed separately for four adjacent peristimulus intervals (indicated by time intervals above each plot). Numbers below each mean indicate the number of action potentials contributing to each mean. 
A

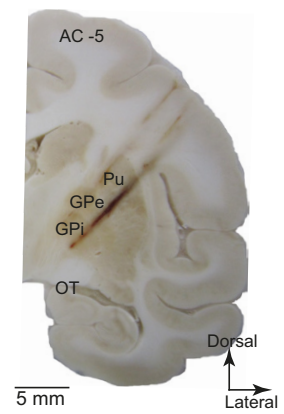

B

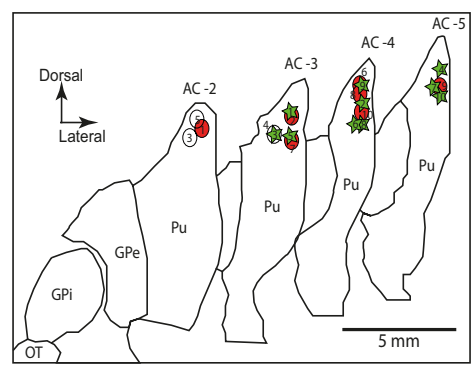

Figure 2. Anatomical reconstruction of injection and recording sites. $A$, Image of coronal section of the left hemisphere from monkey $B$, showing gliosis formed by DBS probe, recording electrode trajectories, and microinjection sites targeting the dorsolateral putamen $\mathrm{AC}-5$. $\mathrm{Pu}$, Putamen; $0 \mathrm{~T}$, optic tract. $\boldsymbol{B}$, Outline drawings reconstructed from the coronal sections of the left hemisphere. The injection sites are projected based on electrophysiological mapping and postmortem reconstructions from each animal and overlaid on the same sections. Circles, Monkey R; stars, monkey B.

tal $(50 \mathrm{mg} / \mathrm{kg})$, and transcardially perfused with saline, followed by $4 \%$ paraformaldehyde. The whole brain was removed and buffered in graded sucrose solution $(10-30 \%)>21 \mathrm{~d}$. The brain was then frozen at $-25^{\circ} \mathrm{C}$ and cut in the coronal plane using a cryostat (LeicaMicrosystems). Each section was digitized using a 10 megapixel digital camera. Contours of brain structures were traced using the digitized images and the anterioposterior position of each injection site was plotted relative to the anterior commissure (AC), taking $\mathrm{AC}=0$ as the origin of the system axes. Injection sites and recording tracks in the basal ganglia were identified via the gliosis formed by the electrodes and injectrode (Fig. 2A). Reconstruction of the stimulating electrode placement was made possible by inserting a stereotaxic marking pin into the GPi at a site that induced therapeutic stimulation just before euthanasia.

\section{Results}

\section{Behavioral effects in reversible tic model}

In each experimental session (total $n=20$ ), microelectrodes were inserted transdurally into the pallidum to monitor neuronal activity, whereas the HF-DBS probe was targeted to the GPi using the same manipulating tower. Once well isolable neurons had been identified in the GPe and GPi, a small amount of bicuculline $(2.0-8.0 \mu \mathrm{l})$ (Table 1)was administered into the sensorimotor putamen. The behavioral response to the microinjection was consistent with previous reports (Crossman et al., 1988; McCairn et al., 2009, 2012, 2013; Worbe et al., 2009; Bronfeld et al., 2011): bicuculline infusion induced repetitive motor tics primarily in the orofacial region within minutes of injections $(7.1 \pm 3.9 \mathrm{~min}$; mean $\pm \mathrm{SD})$ in most of the sessions $(n=17)$ (Table 1$)$. It should be noted that prolonged maintenance of the tic state through supplementary injections of bicuculline (see Materials and Methods) did not allow for the testing of GPi-HF-DBS effects on the overall time that tics were present. Histological examinations confirmed that injections were placed into the sensorimotor territories of the putamen, whereas recording sites and stimulation sites were placed into both segments of GP and GPi, respectively (Fig. 2A). Reconstruction of all the injection sites is shown in Figure $2 B$.

Although the study was principally designed to test for shortterm neuronal effects of GPi-HF-DBS rather than long-term chronic behavioral responses, the $30 \mathrm{~s}$ trains of stimulation were capable of reducing tic-related muscular activity in both animals. Examples of rectified EMG trace are shown in Figure $3 A$, in which periodic voltage deflections correspond to individual tic move-
Table 1. Microinjections, anatomical, and behavioral details

\begin{tabular}{|c|c|c|c|c|c|}
\hline Animal & Injection number & $\mathrm{AC}$ plane $(\mathrm{mm})^{a}$ & Volume $(\mu \mathrm{l})$ & Onset (min) & Effect \\
\hline \multirow[t]{10}{*}{ Monkey R } & 1 & 2 & 2.5 & 1 & Facial/forelimb tics \\
\hline & 2 & 3 & 5 & 6 & Facial tics \\
\hline & 3 & 3 & 8 & - & No effect \\
\hline & 4 & 2 & 8 & - & No effect \\
\hline & 5 & 2 & 8 & - & No effect \\
\hline & 6 & 4 & 4 & 9 & Facial/forelimb tics \\
\hline & 7 & 3.5 & 2.5 & 5 & Facial/forelimb tics \\
\hline & 8 & 4 & 5 & 4 & Facial/forelimb tics \\
\hline & 9 & 4 & 5 & 6 & Facial tics \\
\hline & 10 & 5 & 5 & 5 & Facial tics \\
\hline \multirow[t]{10}{*}{ Monkey B } & 1 & 4 & 8 & 20 & Facial tics \\
\hline & 2 & 3 & 5 & 8 & Facial/forelimb tics \\
\hline & 3 & 3 & 2.5 & 4 & Facial/forelimb tics \\
\hline & 4 & 4 & 5 & 7 & Facial tic \\
\hline & 5 & 3 & 5 & 6 & Facial/forelimb tics \\
\hline & 6 & 4 & 5 & 8 & Facial/forelimb tics \\
\hline & 7 & 4 & 5 & 9 & Facial tic \\
\hline & 8 & 5 & 2.5 & 6 & Facial tic \\
\hline & 9 & 5 & 5 & 9 & Facial/forelimb tic \\
\hline & 10 & 5 & 5 & 8 & Facial tic \\
\hline
\end{tabular}

The anatomical plane at which the injections were placed relative to the anterior commissure. All injections were administered caudally to the anterior commissure.

ments. By plotting the rectified EMG activity aligned to tic onset (Fig. 3B), we confirmed that GPi-HF-DBS significantly reduced the amplitude of tic-related EMG activity $(p<0.001)$ (Fig. $3 B$, see inset for statistical justification). Analysis of the whole dataset showed that the tic frequency was unaffected (Fig. 3C).

\section{Neuronal database}

During the course of the experiment, we recorded from $144 \mathrm{GPe}$ cells and $81 \mathrm{GPi}$ cells during tic states induced by striatal infusion of bicuculline. From this dataset, $66 \mathrm{GPe}$ (Monkey R = 31, Monkey $\mathrm{B}=35$ ) and $53 \mathrm{GPi}$ (Monkey $\mathrm{R}=26$, Monkey $\mathrm{B}=27$ ) cells were exposed to GPi-HF-DBS and satisfied quality control criteria outlined in the methodology. These cells were the main focus of the present study.

\section{Single-cell activity in the pallidum after bicuculline administration}

Consistent with previous reports (McCairn et al., 2009, 2012, 2013; Bronfeld et al., 2011), the majority of pallidal cells exhibited prominent tic-related responses. An example of simultaneously recorded EMG, GPe and GPi activity after tic induction is shown in Figure $4 A$. Within the GPe, 63\% $(n=91 / 144)$ of the recorded cells showed tic-related activity. The most common response was an increase of activity before or coincident with EMG activity $(n=75)$; however, multiphasic $(n=11)$ (Fig. $4 B)$ or inhibitory responses $(n=5)$ were also observed. The earliest neural response was detected $261 \mathrm{~ms}$ before EMG onset (range, -261-296 $\mathrm{ms}$ ) (Fig. $4 \mathrm{C}$ ). In the GPi, tic-related responses were observed in $75 \%$ of the recorded neurons $(n=59 / 81)$. In contrast to the GPe, inhibition was predominant in the GPi $(n=49)$ (Fig. $4 D)$, which was followed by multiphasic responses $(n=8)$ and excitation $(n=2)$. The earliest neural response started $189 \mathrm{~ms}$ before tic onset (range, $-189-130 \mathrm{~ms}$ ) (Fig. $4 E$ ). Although tic related responses were widespread through the pallidum, the earliest responses were observed in the posterior regions. These findings suggest that the firing of pallidal cells in the current animal model was early enough to drive pathological tic behavior. 

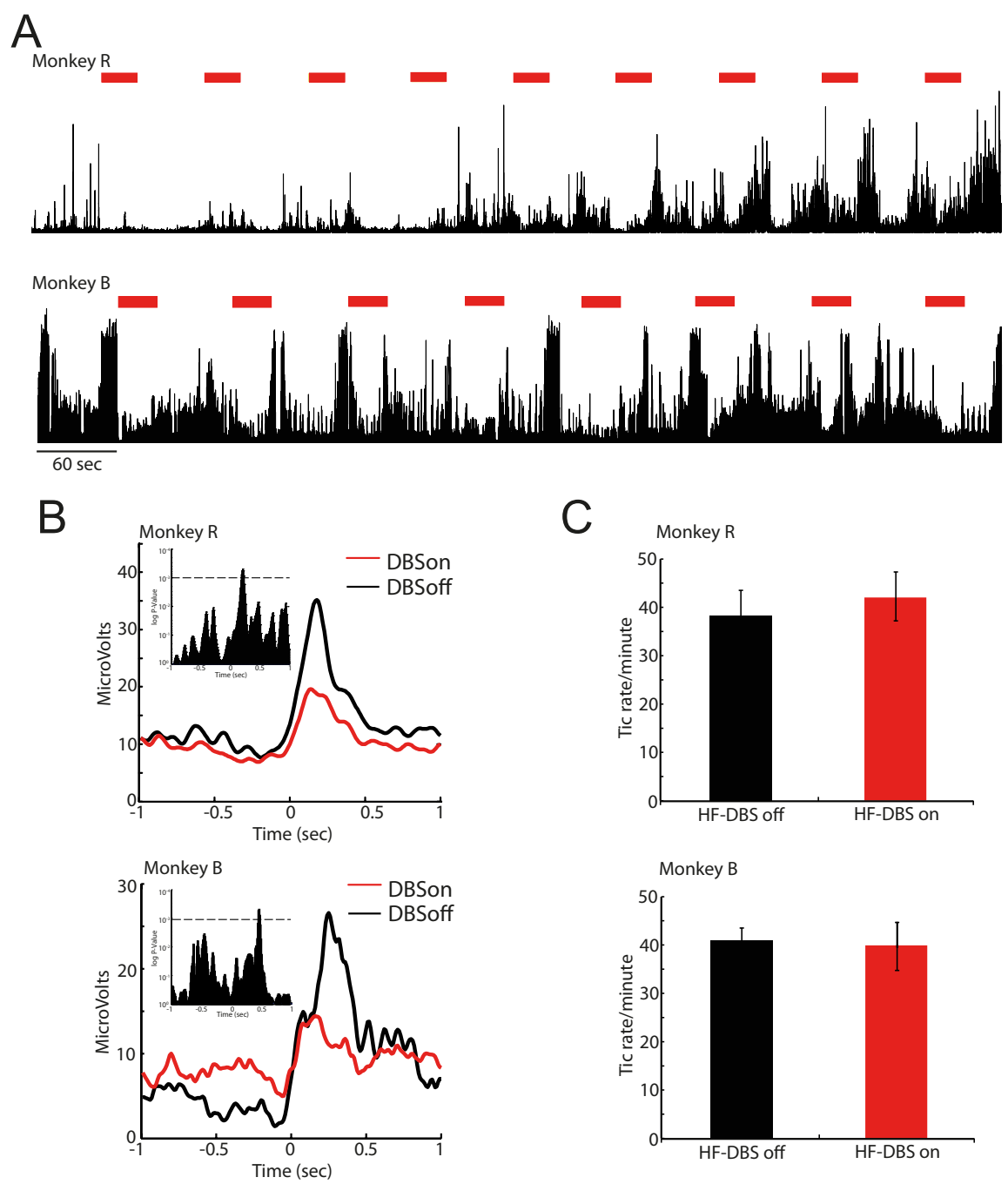

Figure 3. Tic expressions during on- and off-stimulation. $A$, Examples of raw EMG after administration of bicuculline and during HF-DBS. The top trace shows EMG recorded from the orofacial region in monkey $R$; the bottom trace is from monkey $B$; the large voltage transients are tic events. $\boldsymbol{B}$, The reduction of peak voltage amplitude in tic-related EMG. The histogram shows the EMG signals aligned to tic onset. The inset shows a graphical representation of the $t$ test across bins between the two experimental conditions $(p<0.001)$. C, Effects of DBS on tic frequency. The frequency was unchanged by stimulation for both animals.

Effects of GPi-HF-DBS on long-latency mean firing rates GPi-HF-DBS induced significant firing rate changes on the second time scale in the majority of pallidal cells ( $\mathrm{GPe}=75 \%$, $n=50 / 66: \mathrm{GPi}=77 \% n=41 / 53)$. Several distinct response types were expressed in both segments of the pallidum, which included transient excitation (Fig. 5A), transient inhibition, multiphasic responses (Fig. $5 B$ ), sustained excitation, and sustained inhibition. The proportion of each response type is shown in Figure 5E.

To visualize the dynamic changes associated with stimulation, the cells activity was divided into six epochs that covered the $30 \mathrm{~s}$ before and during stimulation (Fig. $5 C, D$ ). A population-scale analysis of mean firing rates using ANOVA showed that a significant increase in firing rates was present for the first $(0-10 \mathrm{~s}$, epoch 4$)$ and second $(10-20$ s, epoch 5$)$ in the GPe $(p=4.8 \times$ $10^{-15}, F=21.21$, Tukey's HSD $)$ and GPi $(p=0.0002, F=5.69$, Tukey's HSD). By the sixth epoch (20-30 s after stimulation onset), however, the population-scale firing rate became nonsignificant compared with baseline in both the GPe $(p=0.07, F=$
2.7, Tukey's HSD $)$ and GPi ( $p=0.18, F=$ 1.65, Tukey's HSD) (Fig. 5C,D).

\section{Suppression of tic-related} pallidal activity

From the dataset of pallidal cells that were exposed to GPi-HF-DBS, $67 \%$ of the cells showed tic-related activity $(n=80 / 119$, $\mathrm{GPe}=50, \mathrm{GPi}=30$ ). By comparing their firing rates between the off-stimulation and on-stimulation conditions, we observed that stimulation was capable of suppressing the phasic tic-related discharges in both segments of the GP (Fig. $6 A, B$, red trace). We found that there was a significant reduction in the proportion of pallidal cells that showed tic-related activity during the on-stimulation condition (DBSoff, $n=80$; DBSon, $n=31 ; \chi^{2}=37.2$ $p<0.0001)$. Although stimulation was active, the neurons that were previously responding to tic events typically still remained active with firing rates often mirroring the stimulation frequency.

To assess whether the suppression of tic-related phasic activity observed in single cells changed the magnitude of population-scale firing rates, we normalized tic-related firing rates to provide a measure of tic activity relative to a baseline of zero for the off-stimulation and on-stimulation condition (Fig. 6C,D). Significant differences between the two states in the peak amplitude of the neuronal activity were tested for by performing a $t$ test across the concatenated offstimulation and on-stimulation matrices of neuronal activity, which gave a $p$ value for each analyzed bin $(10 \mathrm{~ms})$. Our analysis confirmed that GPi-HF-DBS significantly reduced the amplitude of ticrelated phasic changes in neuronal activity for the $\mathrm{GPe}(p<0.00001$; Fig. $6 E)$ and GPi $(p<0.001$; Fig. $6 F)$.

\section{Short-latency responses during GPi-HF-DBS}

To determine how GPi-HF-DBS might eliminate the phasic changes associated with tic-related activity, while maintaining or increasing their firing rates in many of the cells, short-latency neuronal responses in the millisecond range were investigated. Analysis of those cells that were exposed to stimulation found that spiking activity tended to cluster at distinct periods within the interpulse interval (Fig. 7Ai,Bi). This phenomenon, which we called temporal locking, was observed in $70 \%$ of the recorded pallidal cells $(n=83 / 119)$ and caused pronounced phasic changes in mean firing rate of individual cells in the interpulse period. Figure 7, Aii (GPe) and Bii (GPi), quantifies the multiphasic responses from two simultaneously recorded cells during GPi-HF-DBS (averaged across nine stimulation blocks). In the examples shown, a short-latency increase in firing $(0-1.5 \mathrm{~ms})$ was followed by another increase $(2.0-5.0 \mathrm{~ms})$, interspersed by two distinct decreases. These multiphasic effects were relatively consistent across the repeated blocks of stimulation. However, 
A
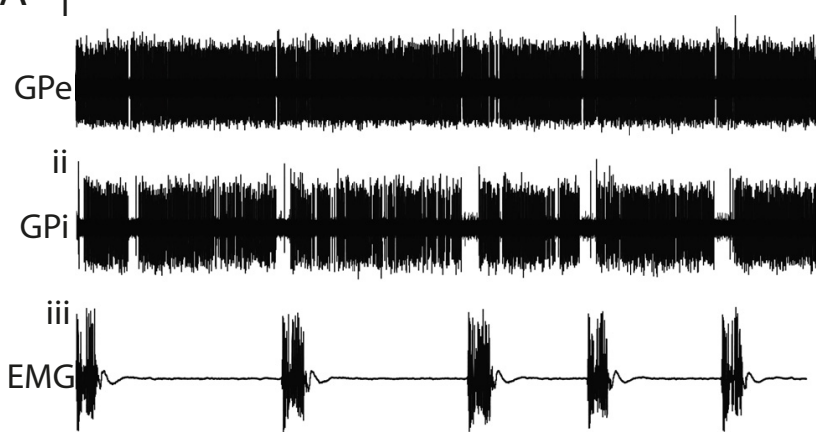

B

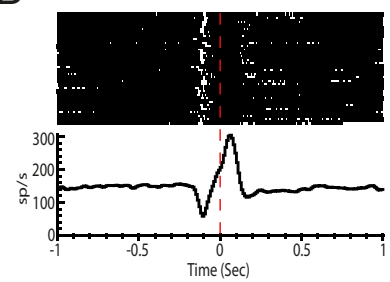

C

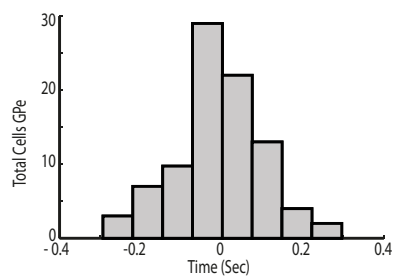

D

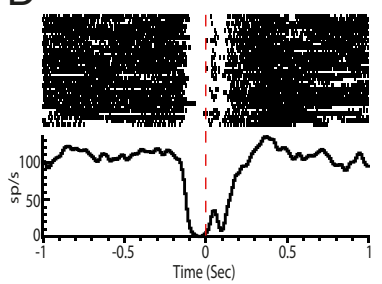

$E$

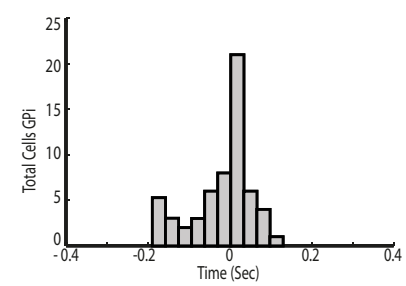

Figure 4. Single-cell recording of pallidal activity during tics. $A$, Examples of raw data from EMG (Aiii) and simultaneously recorded single cell activity in GPe (Ai) and GPi (Aii) after administration of bicuculline. EMG was recorded from the orofacial region. The large voltage transients are tic events. $\boldsymbol{B}$, Perievent raster and histogram of the multiphasic GPe cell shown in $\boldsymbol{A}$. Neuronal activity is aligned to tic onset. $C$, Histogram representing the distribution of response latencies of GPe neurons relative to tic onset. $\boldsymbol{D}$, Perievent raster and histogram of the inhibition-type GPi cell shown in $\boldsymbol{A}$. $\boldsymbol{E}$, Histogram representing the distribution of response latencies of GPi neurons.

their amplitude and temporal profiles evolved over each 30 s block of stimulation. For the examples shown, the short-latency increase $(0-1.5 \mathrm{~ms})$ gradually declined in magnitude across a stimulation block, whereas the later increase $(2.0-5.0 \mathrm{~ms})$ shifted progressively later relative to the stimulus pulse onset as stimulation continued. The phasic modulations of these cells were significant relative to the nonstimulation periods and were equally common across pallidal segments $(\mathrm{GPe}=71 \%, n=47 / 66, \mathrm{GPi}=66 \%, n=$ 35/53). The induction of multiphasic locking with the stimulation pulse was reflected in the population measure of firing rate change in the interpulse period (Fig. $7 C, D$ ), demonstrating that at the network level GPi-HF-DBS induces both excitation and inhibition.

\section{Temporal evolution of short-latency responses}

It was evident from visual examination that many of the cells showing temporal locking displayed significant latency shifts in the later response components. Quantitative analysis of this phenomenon revealed a significant late-phase $(2-5 \mathrm{~ms})$ shift in $88 \%(n=72 / 82)$ of the neurons. Typically, as demonstrated in the examples shown in Figure 7, these responses consisted of slowly increasing latencies with increasing stimulation duration ( $\mathrm{rate}=0.025 \mathrm{~ms} / \mathrm{s}$ ). The prevalence of latency shifts and distributions of their slopes were similar be- tween the two pallidal segments and between phasic increases and decreases in discharge. Collapsing across all cells with temporal locking, it was found that the late component of the phasic responses ( $2-5 \mathrm{~ms})$ occurred significantly later in the sixth stimulation epoch (20-30 s after stimulation onset) than in the fourth stimulation epoch $[0-10 \mathrm{~s}$ after stimulation onset; onset latency (mean $\pm \mathrm{SE}$ ), epoch $1=2.9 \mathrm{~ms} \pm 0.1 \mathrm{vs}$ epoch $3=4.1 \mathrm{~ms} \pm 0.13, p=0.001, t$ test $]$. It should be noted that early phasic responses $(0-1.5 \mathrm{~ms})$ also showed slight shifts in latency across the stimulation period, but these changes were minimal and did not reach significance. Although the latency was dynamically changing across the stimulation period, linear regression of the slope timings found that in all cells with significant latency shifts, the response asymptotes within the $30 \mathrm{~s}$ stimulation block $(\mathrm{GPe}=15.4 \mathrm{~s} \pm 0.9, \mathrm{GPi}=14.1 \mathrm{~s} \pm 2.6$; mean \pm SE).

Changes in response magnitude across the stimulation block varied on a cell-by-cell basis. The most dynamic changes in response magnitude occurred within $0-1.5 \mathrm{~ms}$ from the onset of stimulus pulse. It was common for a cell with the early response component to show a significant decrease in magnitude as stimulation progressed (Fig. 7Aii, Bii). It was found that among the 55 cells exhibiting the early phasic response $(0-1.5 \mathrm{~ms}), 51$ (93\%) showed a significant reduction of response amplitude as stimulation progressed (epoch 4 vs epoch 6). For the later component $(2-5 \mathrm{~ms})$, a smaller proportion of cells $(47 \%, n=39 / 83)$ showed a significant reduction in response magnitude.

\section{Antidromic-like nature of short-latency responses}

The short latency response during the $(0-1.5 \mathrm{~ms})$ interval from each stimulus pulse suggests an antidromic nature to activation. To test this possibility, we analyzed the occurrence of collision off-line. Collision-like phenomena was most often observed in cells that showed a "wrap-around" phenomenon in long-latency responses $(n=10)$, i.e., the latency of the increase shifted progressively later across the stimulation block so that it eventually merged with the fixed-latency response at $\sim 1 \mathrm{~ms}$. Figure $8 \mathrm{~A}$ illustrates an example of a GPi cell in which the wrap around and collision-like phenomena were clearly seen. Analysis of the cells activity in the interpulse period confirmed that the early driven response occurred at a fixed latency (Fig. 8Bi). However, when spontaneous spikes occurred immediately before stimulation pulses the cells failed to respond (Fig. 8Bii). In convention with our previous studies (McCairn and Turner, 2009) which also reported this phenomenon, we termed the effect "antidromiclike," because collision analysis was performed off-line and it was not possible to apply definitive tests for antidromic activation (e.g., testing for a fixed collision interval). Consistent with previous reports, the rates of failure were high for all antidromic-like responses, ranging in this study between $69 \%$ and $86 \%$, similar to those reported for direct activation during STN DBS (Garcia et al., 2003) and to our previous studies using pallidal stimulation in parkinsonian primates (McCairn and Turner, 2009).

\section{Discussion}

We used a NHP model of motor tics to study the efficacy and neuronal correlates of GPi-HF-DBS. In this model, abnormal tic movements were acute and reversible: they emerged within minutes of drug injection and then disappeared a few hours later. Application of GPi-HF-DBS reduced the amplitude of florid motor tics induced by striatal disinhibition. The mechanism of symptom reduction at the neuronal level involves suppression of phasic tic-related modulations of pallidal activity. This suppression is most likely caused by cellular activity temporally locking with the stimulation pulse, which 


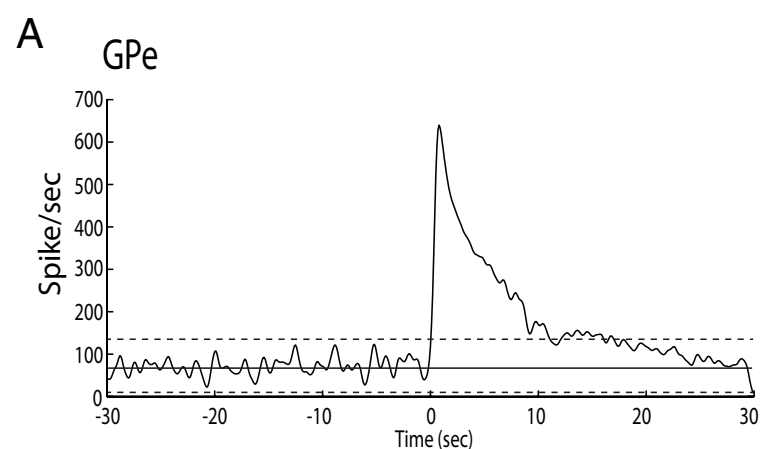

C
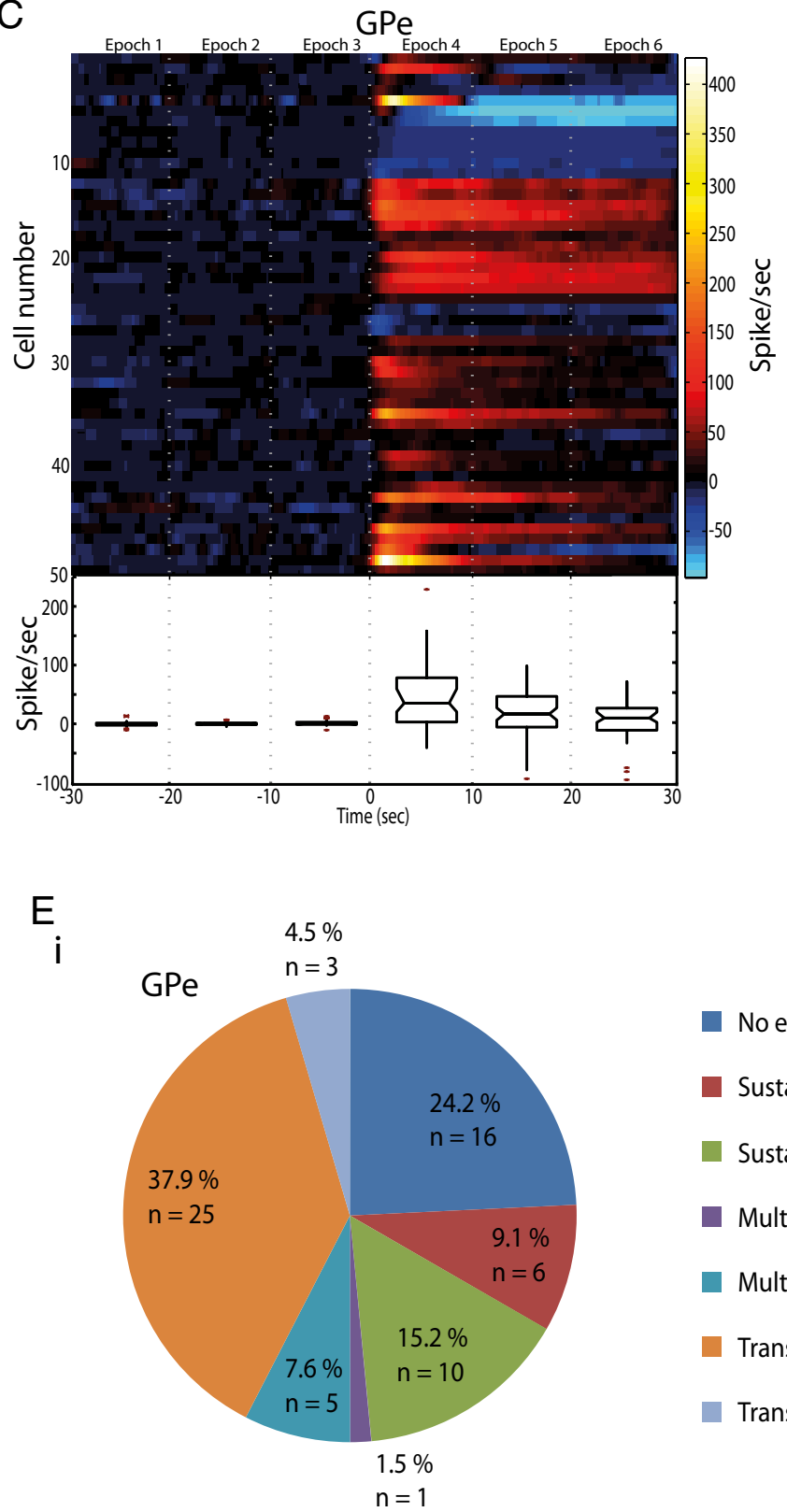

B

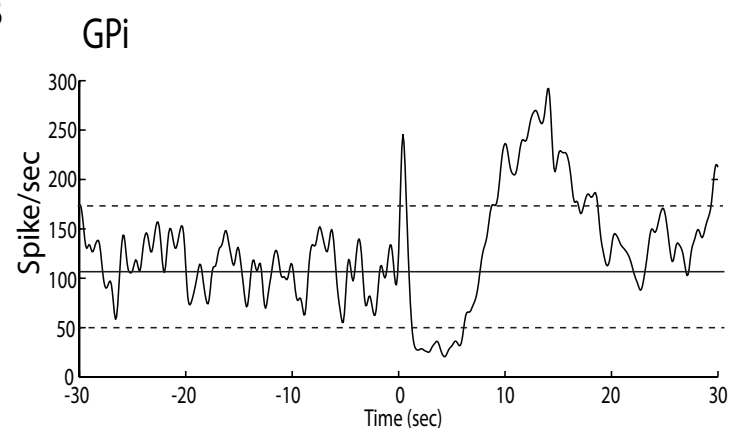

$\mathrm{D}$

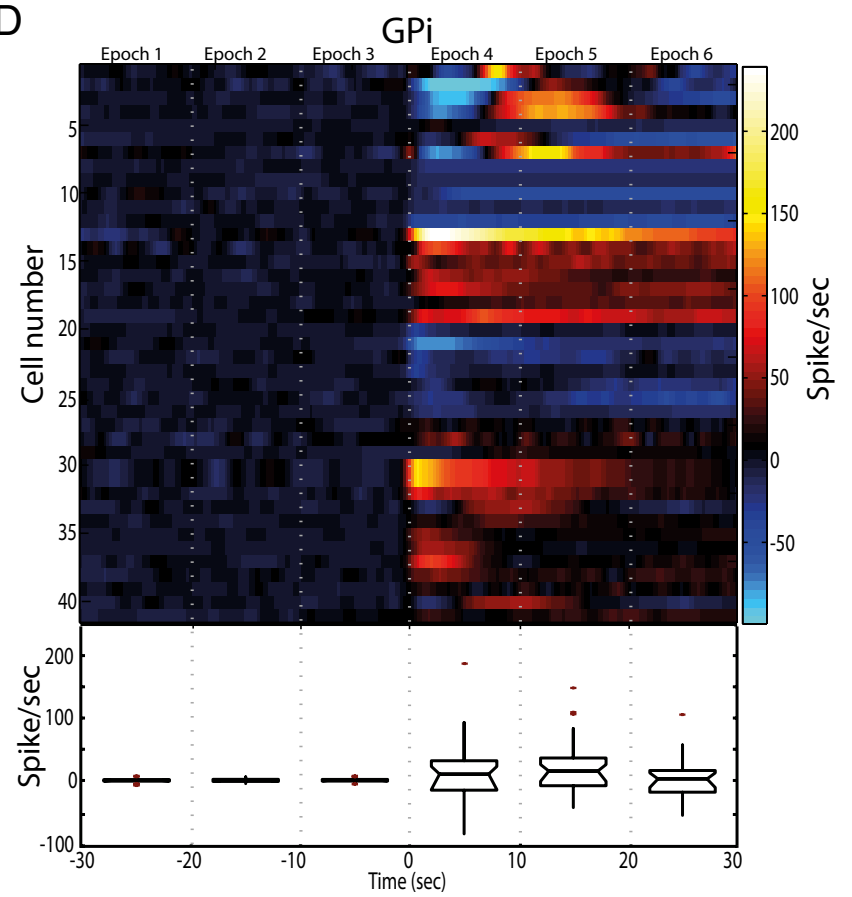

ii

No effect

- Sustained inhibition

- Sustained excitation

Multiphasic - +

Multiphasic +-

Transient excitation

Transient inhibition

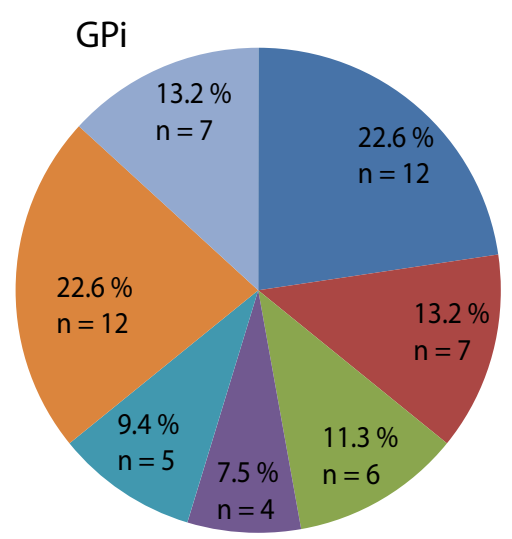

Figure 5. Long-latency pallidal responses to GPi-HF-DBS. $A$, Peristimulus histogram aligned to DBS onset (time $=0$ ) for a transiently excited GPe cell. The firing rate returned to control levels while stimulation was still active. $\boldsymbol{B}$, An example of a GPi cell showing multiphasic changes of firing rates. $\boldsymbol{C}, \boldsymbol{D}$, Population response to DBS for the GPe $(\boldsymbol{C})$ and GPi $(\boldsymbol{D})$. The color matrix showing individual cells discharge is aligned to DBS onset (time $=0$ ). The box-and-whisker plot shows the median and range of HF-DBS induced firing rate changes for each $10 \mathrm{~s} s$ timulation epoch before and during stimulation. The horizontal ends of each box indicate upper and lower quartile values; whiskers are extended to the most extreme value 1.5 fold the interquartile range. Notches in the side of the boxes display the $95 \%$ confidence interval. Outliers are displayed as + . E, Pie charts indicating the proportion of each type of long-latency effect in GPe (Ei) and GPi (Eii). 
A

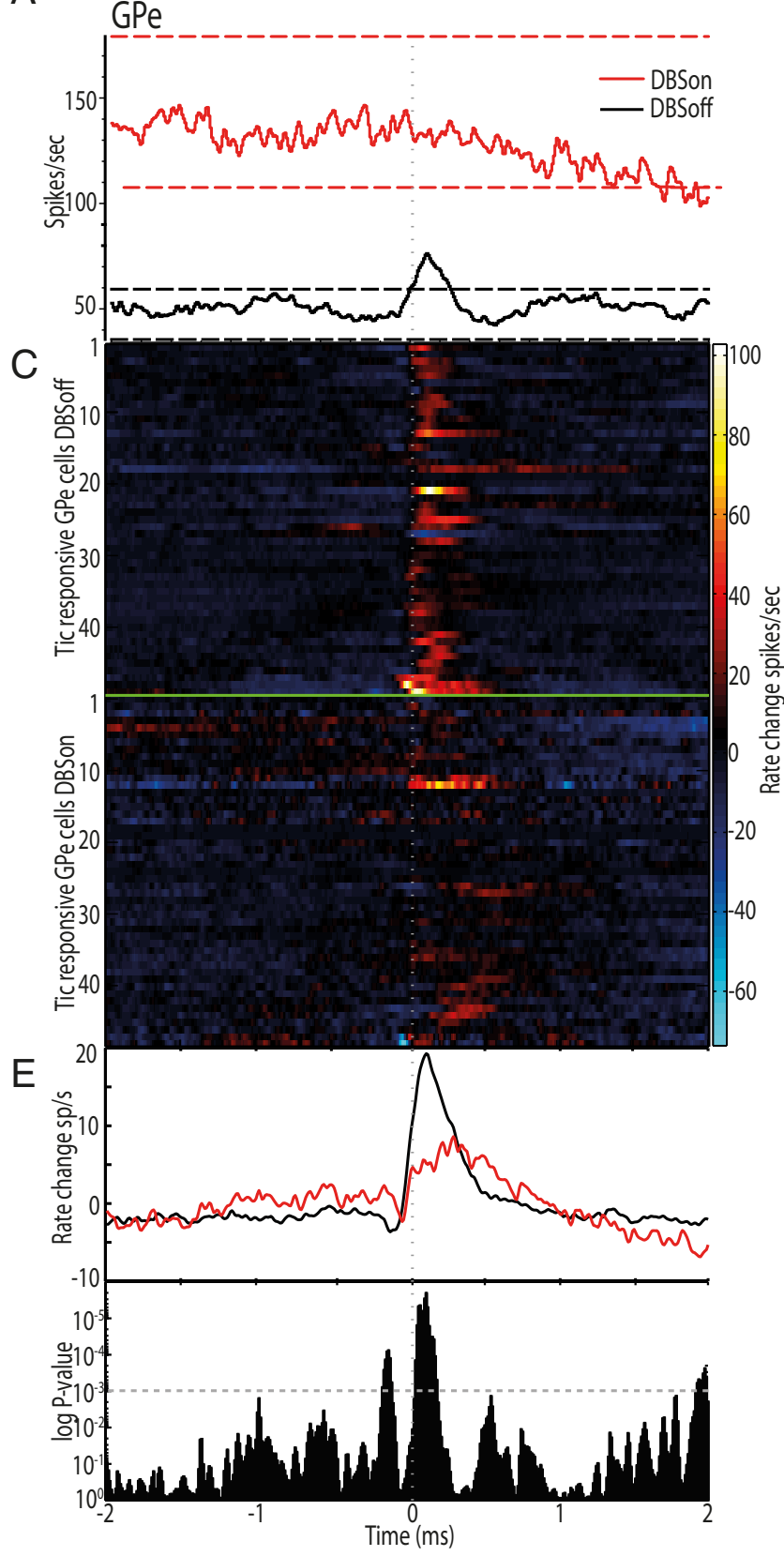

B

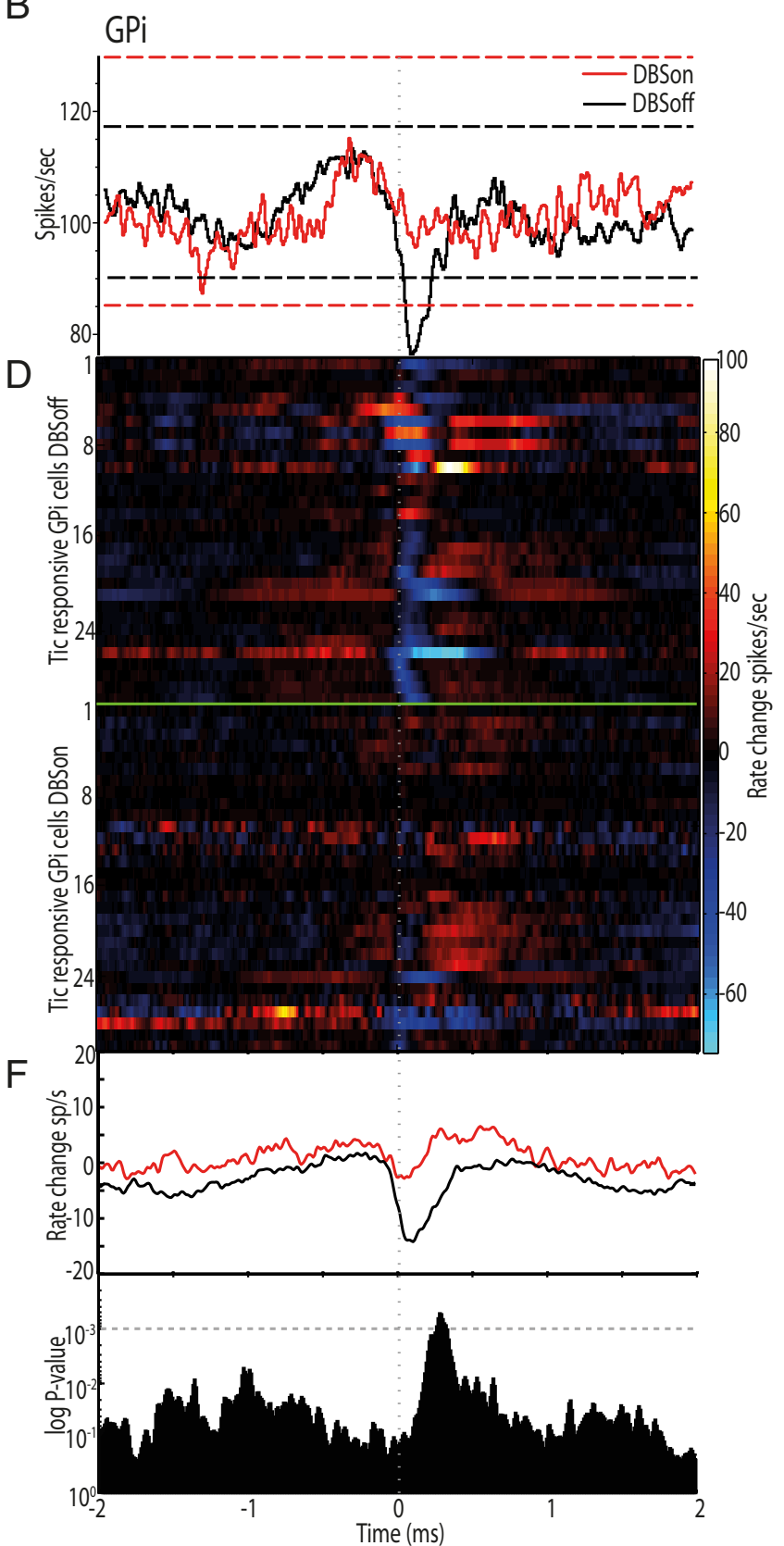

Figure 6. Suppression and reduction of tic-related neuronal activity during GPi-HF-DBS. A, Modulation of activity in a tic-responsive GPe neuron during off-stimulation (black trace) and on-stimulation (red trace). Neuronal activity is aligned to tic onset. The horizontal dashed lines represent confidence intervals of $99 \%$ and are color-coded to each condition. $\boldsymbol{B}$, Modulation of activity in a tic-responsive GPi neuron during off-stimulation (black trace) and on-stimulation (red trace). The activity is aligned to tic onset. $\boldsymbol{C}, \boldsymbol{D}$, Plots showing the response of each tic-responsive cell in the $\mathrm{GPe}(\boldsymbol{C})$ and $\mathrm{GPi}(\boldsymbol{D})$ in the off-stimulation (top trace) and on-stimulation (bottom trace) condition. Note the prevalence of excitatory (GPe) and inhibitory (GPi) responses. $\boldsymbol{E}, \boldsymbol{F}$, The mean activity changes for the population of $\mathrm{GPe}(\boldsymbol{E})$ and $\mathrm{GPi}(\boldsymbol{F})$ neurons during off-stimulation (black trace) and on-stimulation (red trace). $p$ values are shown below to indicate significant differences between the two stimulation conditions.

induces at the population level a multiphasic pattern of excitation and inhibition in the interpulse period.

\section{Tic-related neuronal activity during off-stimulation} and on-stimulation

Consistent with previous reports, focal disinhibition of the striatum with bicuculline induced myoclonic-like motor tics, and the expression of tics was associated with widespread phasic changes in pallidal activity, suggesting that aberrant BG output leads to tourettism (McCairn et al., 2009, 2012, 2013; Bronfeld et al., 2011). It was our experience that periodic tic-related discharge was widespread in the GP, but early responding cells were localized in its posterior region. This region corresponds to those that receive the largest topographical projections from the corticostriatal motor system (Francois et al., 1984; Parent et al., 1984; Smith and Parent, 1986; Haber et al., 1990; Hedreen and DeLong, 1991). Having identified this region, we focused our recording efforts to sampling from this particular area. During GPi-HFDBS, it was observed that stimulation could significantly reduce the proportion of tic-responding cells in the pallidum. This reduction was evident in the population-scale phasic change in firing rate, which was highly significant for the both GPe and GPi. 

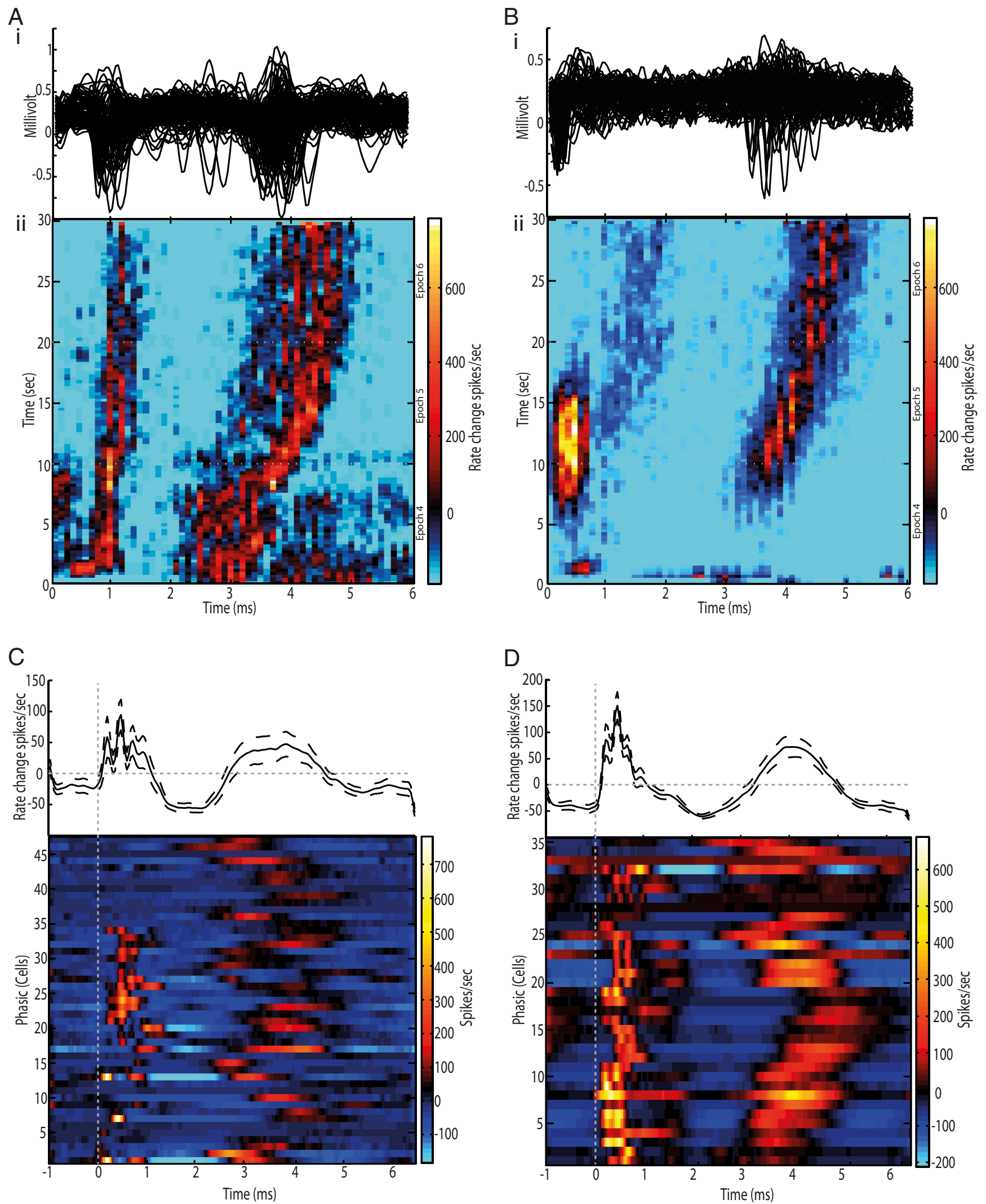

Figure 7. Short-latency pallidal responses to GPi-HF-DBS. $\boldsymbol{A i}$, Bi, Unprocessed peristimulus sweeps of extracellular potentials for a GPe (Ai) and GPi (Bi) cell. Note two clusters of action potentials, which is indicative of temporal locking with the stimulus pulse. Aii, Bii, The peristimulus histogram versus time plots for the above neurons. The color matrix shows the magnitude of firing rate changes relative to baseline across the interpulse period (abscissa) and the $30 \mathrm{~s} \mathrm{stimulation} \mathrm{block} \mathrm{(ordinate).} \mathrm{The} \mathrm{early} \mathrm{and} \mathrm{late} \mathrm{excitatory} \mathrm{phases} \mathrm{are} \mathrm{bounded} \mathrm{by} \mathrm{periods} \mathrm{of} \mathrm{inhibition.} \mathrm{Also,} \mathrm{note} \mathrm{the}$ fixed latency of the early excitatory component $(0-1.5 \mathrm{~ms})$, whereas a gradual shift of the later excitatory component. $\boldsymbol{C}, \boldsymbol{D}$, Population summaries of the short-latency effects in GPe $(\boldsymbol{C})$ and $\mathrm{GPi}(\boldsymbol{D})$. Shown are firing rate changes aligned to each stimulus pulse for the population of neurons (top trace) and individual neurons (bottom trace). 
A

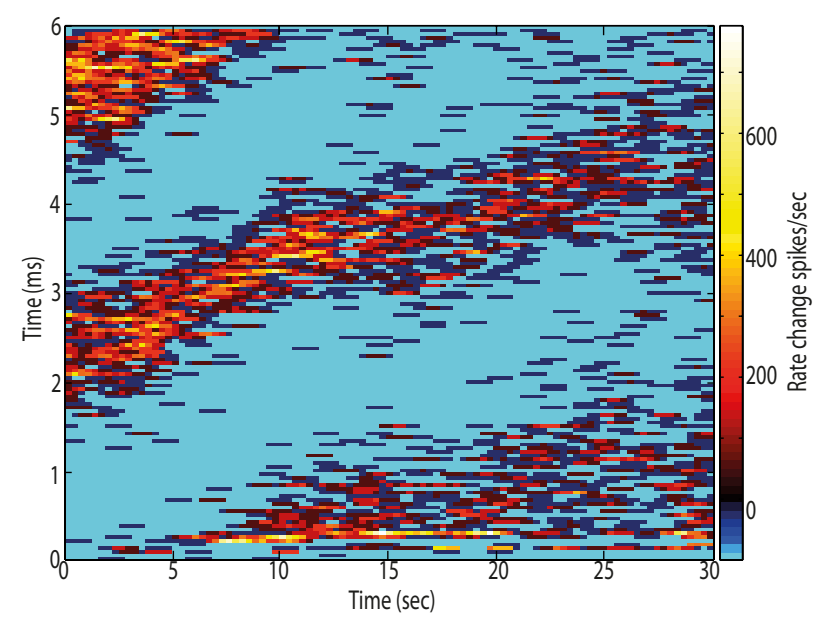

B

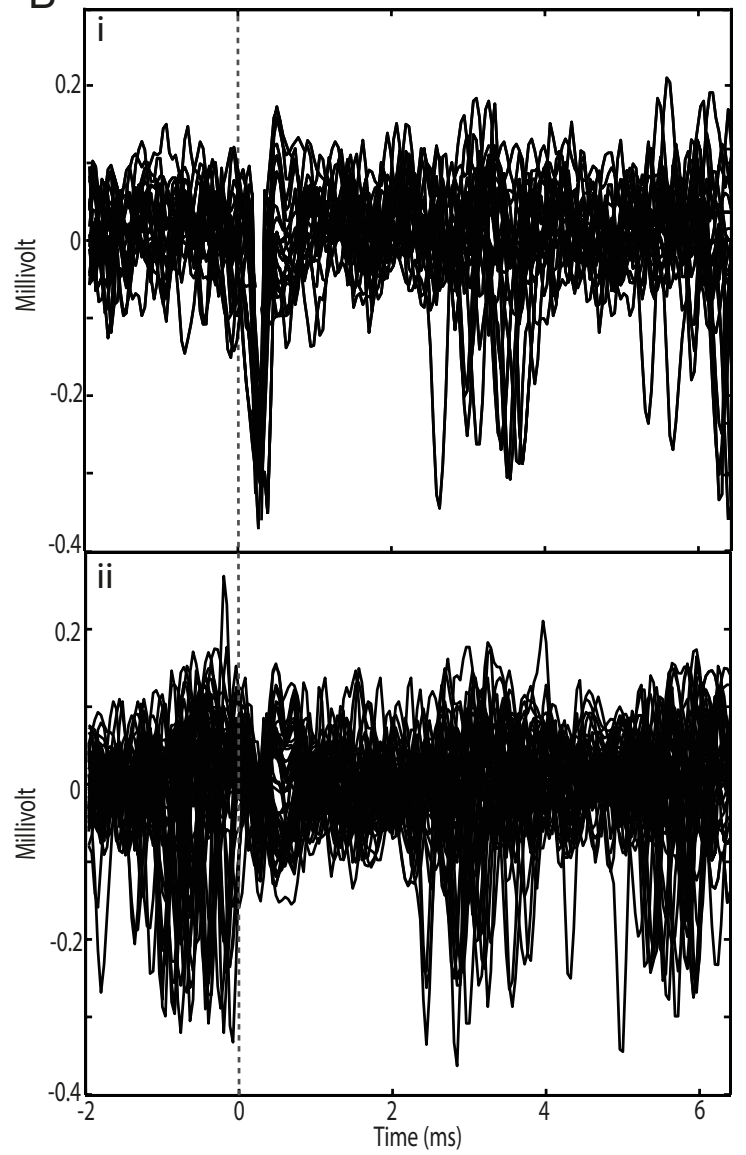

Figure 8. Wrap-around phenomenon and antidromic-like activation. $A$, A GPi cell showing the wrap-around phenomenon. Note the late cluster at $5-6 \mathrm{~ms}$ from stimulus onset. The color matrix shows the magnitude of firing rate changes relative to baseline across the interpulse period (ordinate) and the 30 s stimulation block (abscissa). Bi, Antidromic-like action potentials at a short fixed latency following stimulation delivery (vertical dotted line). Bii, Collision-like phenomenon. Stimulation failed to evoke action potentials when spontaneous spikes occurred immediately before stimulation delivery.

Inhibition/suppression was not the principal effect of GPi-HF-DBS

A long-standing hypothesis as to why HF-DBS is effective in movement disorders stems from the similarity between effects of pallidotomy and those of HF-DBS in Parkinson's disease (Benabid et al., 1991; Benazzouz and Hallett, 2000). In this study, we found minimal effects on population-scale mean firing rates, contrary to the predictions of the inactivation/suppression hypotheses (Fig. 5). We observed a sustained reduction in firing in a subset of neurons, but such reductions were countered by the large increase in baseline firing rates of the phasically responding neurons that were more common. Although caution should be used when comparing the effects of HF-DBS in a hyper-kinetic condition to those observed in parkinsonian patients and disease models, it should be noted that the results obtained in this study are consistent with previous observations made in parkinsonian monkeys receiving GPi-HF-DBS (Bar-Gad et al., 2004; Erez et al., 2009; McCairn and Turner, 2009). Reports of HF-DBS-induced phasic driving in efferent-recipient nuclei and observations of HF-DBS-induced changes in neurotransmitter concentrations lend further support against the inactivation hypothesis (Windels et al., 2000; Bruet et al., 2001; Anderson et al., 2003; Hashimoto et al., 2003; Stefani et al., 2005).

\section{Multiphasic responses were common during GPi-HF-DBS}

Multiphasic modulations of pallidal activity induced by HF-DBS have been consistently reported in the literature with respect to use of this methodology in parkinsonian models (Anderson et al., 2003; Hashimoto et al., 2003; Bar-Gad et al., 2004; Erez et al., 2009; McCairn and Turner, 2009; Liu et al., 2012). Consistent with parkinsonian studies, we found abundant multiphasic driving in both pallidal segments during GPi-HF-DBS, with similar response prevalence to our previous study using the same stimulation procedure in MPTP primates (McCairn and Turner, 2009). In this study and previous studies, we identified many short-latency responses as "antidromic-like" driving on the basis of the fixed-latency spike generation in response to stimulation pulses (Fig. 8) and the absence of significant latency shifts (McCairn and Turner, 2009). We also observed collision-like phenomena, albeit tested off-line, in all short-latency datasets that had a "wrap-around" phenomenon. The consistent in vivo reports of antidromic-like effects in setups that allowed their identification using proper artifact cancellation procedures ( $\mathrm{Li}$ et al., 2007; McCairn and Turner, 2009; Liu et al., 2012) suggests that antidromic driving is a feature of therapeutic HF-DBS.

Antidromic driving is a phenomenon predicted for the local effects of DBS based on basic knowledge about the effects of electrical stimulation on neuronal tissue (Ranck, 1975; McIntyre et al., 2004a). Support for antidromic-like driving being a component of the DBS effect also comes from observations in intracellular recordings from STN slice preparations (Garcia et al., 2003, 2005). In addition, short-latency responses in GPe are consistent with known GPe-to-GPi connectivity and predictions from modeling studies (McIntyre and Grill, 2000; McIntyre et al., 2004b).

There are a number of mechanisms and pathways that could mediate the later, dynamic components of the phasic responses (inhibition/excitation). The most probable mechanism for the firing rate reduction, which followed phasic increases, is the induction of refractory periods. Activation of GABAergic afferents from the striatum (Hedreen and DeLong, 1991), afferents from the other pallidal segment (Nambu and Llinas, 1994; Sato et al., 2000a), and local axon collaterals (Parent et al., 2001) may also account for the observed reductions. Axonal activation of collateralized glutamatergic afferents from the STN (Sato et al., 2000b) and pedunculopontine nucleus (Gonya-Magee and Anderson, 1983; Scarnati et al., 1988) could account for the longer-latency increases (3-5 ms) 
in both pallidal segments. In addition, multisynaptic reentrant pathways via thalamostriatal, corticostriatal, corticosubthalamic, and brainstem pathways could also contribute to the observed response (DeLong and Wichmann, 2007). Postinhibition rebound may also contribute to some long-latency increases (Nambu and Llinas, 1994).

Plasticity is now beginning to be recognized as a component of HF-DBS (Tass and Majtanik, 2006; Erez et al., 2009; McCairn and Turner, 2009; Liu et al., 2012). This premise is supported by the long-latency ( $>2.0 \mathrm{~ms}$ ) response components in the current and previous studies that have been shown to shift their timing and magnitude across stimulation blocks, presumably via synaptically mediated mechanisms (Hammond et al., 2007; Liu et al., 2012). It has also been suggested that a build-up of network-level resonance is an important component of the therapeutic response to HF-DBS (Montgomery and Gale, 2008). The gradual evolution of GPi-HFDBS-mediated neuronal responses, as seen in the present study, may be consistent with this hypothesis. However, the mechanisms mediating these changes are still a matter of speculation due to a number of potential pathways involved and insufficient knowledge of their physiology.

\section{Clinical relevance}

Since the first reports of success in using HF-DBS to treat TS (Vandewalle et al., 1999), a number of different targets have been suggested to have therapeutic potential. These targets are covered by five brain regions: (1) the GPi, (2) the GPe, (3) the medial thalamus, (4) the nucleus accumbens, and (5) the STN (Ackermans et al., 2012). It is highly likely that because of the tight interconnection of the above BG structures, the effects of stimulation in one region will have profound effects on any upstream and downstream structures. Therefore, although the chosen target might not be the specific locus of the pathology associated with TS, its stimulation would block propagation of pathological signals through its local network and thus reduce aberrant signals in downstream structures. It is also likely that orthodromic and antidromic effects will have a considerable impact on nearby networks; this phenomenon has been observed in other HF-DBS models (Anderson et al., 2003; Hashimoto et al., 2003; Montgomery, 2006; Johnson et al., 2009).

There remains much debate within scientific community as to which regions of the pallidum are the best sites for electrode implantation. Recent work has suggested that the GPe may be a useful clinical target (Piedimonte et al., 2012), although others also suggest that in the GPi both posteroventral sensorimotor (van der Linden et al., 2002; Shahed et al., 2007; Dehning et al., 2008; Dueck et al., 2009; Martinez-Fernandez et al., 2011) and associative/limbic anteromedial regions (Houeto et al., 2005; Welter et al., 2008; Martinez-Fernandez et al., 2011) are effective sites. The data from this study showed that posterior regions were effective; this observation though should be taken with the caveat that the tics observed in this model were induced by focal abnormalities placed into the dorsolateral putamen, which projects strongly to the posterior sensorimotor pallidum. Therefore, the most efficacious site is likely dependent on where the underlying pathology is located: i.e., if the abnormality were located more within limbic/associative regions then anteromedial regions of the pallidum would be the optimal choice.

A notable methodological constraint of the current investigation is that HF-DBS was only applied for short 30 s periods, which is in contrast with the continuous use of HF-DBS in clinical settings over months to years. The results from the study do not rule out the possibility that additional phenomena arise minutes/hours/days after chronic stimulation. However, there is little question that the neuronal effects described here were associated with clinical effects within seconds of GPi-HF-DBS onset.

\section{Conclusion}

Emerging evidence continues to suggest that GPi-HF-DBS is an effective treatment for intractable TS and motor tics (van der Linden et al., 2002; Houeto et al., 2005; Shahed et al., 2007; Dehning et al., 2008; Dueck et al., 2009; Welter et al., 2010; AzoulayZyss et al., 2011; Martinez-Fernandez et al., 2011). These clinical reports have also been supported by studies using NHPs (Baup et al., 2008; McCairn et al., 2012). We now expand the previous studies by showing that the suppression of tic-related neuronal activity is associated with a temporal locking of spiking activity with the stimulation pulse, which induces complex patterns of excitation and inhibition in affected cells. We propose that the temporal locking observed in the output nucleus of the BG reduces the transmission of aberrant information from the striatum through BG networks, thereby reducing its impact on cortical centers that drive motor tics. Future studies should investigate the downstream structures to the pallidum to determine whether this is the case.

\section{References}

Ackermans L, Kuhn J, Neuner I, Temel Y, Visser-Vandewalle V (2012) Surgery for Tourette syndrome. World Neurosurg. Advance online publication. Retrieved March 6, 2013. doi:10.1016/j.wneu.2012.06.017. CrossRef Medline

Albin RL, Mink JW (2006) Recent advances in Tourette syndrome research. Trends Neurosci 29:175-182. CrossRef Medline

Anderson ME, Postupna N, Ruffo M (2003) Effects of high-frequency stimulation in the internal globus pallidus on the activity of thalamic neurons in the awake monkey. J Neurophysiol 89:1150-1160. CrossRef Medline

Azoulay-Zyss J, Roze E, Welter ML, Navarro S, Yelnik J, Clot F, Bardinet E, Karachi C, Dormont D, Galanaud D, Pidoux B, Cornu P, Vidailhet M, Grabli D (2011) Bilateral deep brain stimulation of the pallidum for myoclonus-dystonia due to epsilon-sarcoglycan mutations: a pilot study. Arch Neurol 68:94-98. CrossRef Medline

Bar-Gad I, Elias S, Vaadia E, Bergman H (2004) Complex locking rather than complete cessation of neuronal activity in the globus pallidus of a 1-methyl-4-phenyl-1,2,3,6-tetrahydropyridine-treated primate in response to pallidal microstimulation. J Neurosci 24:7410-7419. CrossRef Medline

Baup N, Grabli D, Karachi C, Mounayar S, François C, Yelnik J, Féger J, Tremblay L (2008) High-frequency stimulation of the anterior subthalamic nucleus reduces stereotyped behaviors in primates. J Neurosci 28: 8785-8788. CrossRef Medline

Benabid AL, Pollak P, Gervason C, Hoffmann D, Gao DM, Hommel M, Perret JE, de Rougemont J (1991) Long-term suppression of tremor by chronic stimulation of the ventral intermediate thalamic nucleus. Lancet 337:403-406. CrossRef Medline

Benazzouz A, Hallett M (2000) Mechanism of action of deep brain stimulation. Neurology 55:S13-S16. Medline

Bronfeld M, Belelovsky K, Bar-Gad I (2011) Spatial and temporal properties of tic-related neuronal activity in the cortico-basal ganglia loop. J Neurosci 31:8713-8721. CrossRef Medline

Bronstein JM, et al. (2011) Deep brain stimulation for Parkinson disease: an expert consensus and review of key issues. Arch Neurol 68:165. CrossRef Medline

Bruet N, Windels F, Bertrand A, Feuerstein C, Poupard A, Savasta M (2001) High frequency stimulation of the subthalamic nucleus increases the extracellular contents of striatal dopamine in normal and partially dopaminergic denervated rats. J Neuropathol Exp Neurol 60:15-24. Medline

Crossman AR, Mitchell IJ, Sambrook MA, Jackson A (1988) Chorea and myoclonus in the monkey induced by gamma-aminobutyric acid antagonism in the lentiform complex: the site of drug action and a hypothesis for the neural mechanisms of chorea. Brain 111:1211-1233. Medline 
Dehning S, Mehrkens JH, Müller N, Bötzel K (2008) Therapy-refractory Tourette syndrome: beneficial outcome with globus pallidus internus deep brain stimulation. Mov Disord 23:1300-1302. CrossRef Medline

DeLong MR (1971) Activity of pallidal neurons during movement. J Neurophysiol 34:414-427. Medline

DeLong MR (1972) Activity of basal ganglia neurons during movement. Brain Res 40:127-135. CrossRef Medline

DeLong MR, Wichmann T (2007) Circuits and circuit disorders of the basal ganglia. Arch Neurol 64:20-24. CrossRef Medline

Dueck A, Wolters A, Wunsch K, Bohne-Suraj S, Mueller JU, Haessler F, Benecke R, Buchmann J (2009) Deep brain stimulation of globus pallidus internus in a 16-year-old boy with severe Tourette syndrome and mental retardation. Neuropediatrics 40:239-242. CrossRef Medline

Erez Y, Czitron H, McCairn K, Belelovsky K, Bar-Gad I (2009) Short-term depression of synaptic transmission during stimulation in the globus pallidus of 1-methyl-4-phenyl-1,2,3,6-tetrahydropyridine-treated primates. J Neurosci 29:7797-7802. CrossRef Medline

Francois C, Percheron G, Yelnik J (1984) Localization of nigrostriatal, nigrothalamic and nigrotectal neurons in ventricular coordinates in macaques. Neuroscience 13:61-76. CrossRef Medline

Garcia L, Audin J, D’Alessandro G, Bioulac B, Hammond C (2003) Dual effect of high-frequency stimulation on subthalamic neuron activity. J Neurosci 23:8743-8751. Medline

Garcia L, D’Alessandro G, Fernagut PO, Bioulac B, Hammond C (2005) Impact of high-frequency stimulation parameters on the pattern of discharge of subthalamic neurons. J Neurophysiol 94:3662-3669. CrossRef Medline

Gonya-Magee T, Anderson ME (1983) An electrophysiological characterization of projections from the pedunculopontine area to entopeduncular nucleus and globus pallidus in the cat. Exp Brain Res 49:269-279. Medline

Haber SN, Lynd E, Klein C, Groenewegen HJ (1990) Topographic organization of the ventral striatal efferent projections in the rhesus monkey: an anterograde tracing study. J Comp Neurol 293:282-298. CrossRef Medline

Hammond C, Bergman H, Brown P (2007) Pathological synchronization in Parkinson's disease: networks, models and treatments. Trends Neurosci 30:357-364. CrossRef Medline

Hashimoto T, Elder CM, Okun MS, Patrick SK, Vitek JL (2003) Stimulation of the subthalamic nucleus changes the firing pattern of pallidal neurons. J Neurosci 23:1916-1923. Medline

Hedreen JC, DeLong MR (1991) Organization of striatopallidal, striatonigral, and nigrostriatal projections in the macaque. J Comp Neurol 304: 569-595. CrossRef Medline

Houeto JL, Karachi C, Mallet L, Pillon B, Yelnik J, Mesnage V, Welter ML, Navarro S, Pelissolo A, Damier P, Pidoux B, Dormont D, Cornu P, Agid Y (2005) Tourette's syndrome and deep brain stimulation. J Neurol Neurosurg Psychiatry 76:992-995. CrossRef Medline

Johnson MD, Vitek JL, McIntyre CC (2009) Pallidal stimulation that improves parkinsonian motor symptoms also modulates neuronal firing patterns in primary motor cortex in the MPTP-treated monkey. Exp Neurol 219:359-362. CrossRef Medline

Kalanithi PS, Zheng W, Kataoka Y, DiFiglia M, Grantz H, Saper CB, Schwartz ML, Leckman JF, Vaccarino FM (2005) Altered parvalbumin-positive neuron distribution in basal ganglia of individuals with Tourette syndrome. Proc Natl Acad Sci U S A 102:13307-13312. CrossRef Medline

Kataoka Y, Kalanithi PS, Grantz H, Schwartz ML, Saper C, Leckman JF, Vaccarino FM (2010) Decreased number of parvalbumin and cholinergic interneurons in the striatum of individuals with Tourette syndrome. J Comp Neurol 518:277-291. CrossRef Medline

Krauss JK, Pohle T, Weber S, Ozdoba C, Burgunder JM (1999) Bilateral stimulation of globus pallidus internus for treatment of cervical dystonia. Lancet 354:837-838. CrossRef Medline

Kusama T, Mabuchi M (1970) Stereotaxic atlas of the brain of macaca fuscata. Tokyo: University of Tokyo.

Lerner A, Bagic A, Simmons JM, Mari Z, Bonne O, Xu B, Kazuba D, Herscovitch P, Carson RE, Murphy DL, Drevets WC, Hallett M (2012) Widespread abnormality of the gamma-aminobutyric acid-ergic system in Tourette syndrome. Brain 135:1926-1936. CrossRef Medline

Li S, Arbuthnott GW, Jutras MJ, Goldberg JA, Jaeger D (2007) Resonant antidromic cortical circuit activation as a consequence of high-frequency subthalamic deep-brain stimulation. J Neurophysiol 98:3525-3537. CrossRef Medline

Liu LD, Prescott IA, Dostrovsky JO, Hodaie M, Lozano AM, Hutchison WD (2012) Frequency-dependent effects of electrical stimulation in the globus pallidus of dystonia patients. J Neurophysiol 108:5-17. CrossRef Medline

Martinez-Fernandez R, Zrinzo L, Aviles-Olmos I, Hariz M, Martinez-Torres I, Joyce E, Jahanshahi M, Limousin P, Foltynie T (2011) Deep brain stimulation for gilles de la Tourette syndrome: a case series targeting subregions of the globus pallidus internus. Mov Disord 26:1922-1930. CrossRef Medline

Martinez-Torres I, Hariz MI, Zrinzo L, Foltynie T, Limousin P (2009) Improvement of tics after subthalamic nucleus deep brain stimulation. Neurology 72:1787-1789. CrossRef Medline

McCairn KW, Turner RS (2009) Deep brain stimulation of the globus pallidus internus in the parkinsonian primate: local entrainment and suppression of low-frequency oscillations. J Neurophysiol 101:1941-1960. CrossRef Medline

McCairn KW, Bronfeld M, Belelovsky K, Bar-Gad I (2009) The neurophysiological correlates of motor tics following focal striatal disinhibition. Brain 132:2125-2138. CrossRef Medline

McCairn KW, Iriki A, Isoda M (2012) High-frequency pallidal stimulation eliminates tic-related neuronal activity in a nonhuman primate model of Tourette syndrome. Neuroreport 23:206-210. CrossRef Medline

McCairn KW, Iriki A, Isoda M (2013) Global dysrhythmia of cerebro-basal ganglia-cerebellar networks underlies motor tics following striatal disinhibition. J Neurosci 33:697-708. CrossRef Medline

McIntyre CC, Grill WM (2000) Selective microstimulation of central nervous system neurons. Ann Biomed Eng 28:219-233. CrossRef Medline

McIntyre CC, Grill WM, Sherman DL, Thakor NV (2004a) Cellular effects of deep brain stimulation: model-based analysis of activation and inhibition. J Neurophysiol 91:1457-1469. CrossRef Medline

McIntyre CC, Savasta M, Kerkerian-Le Goff L, Vitek JL (2004b) Uncovering the mechanism(s) of action of deep brain stimulation: activation, inhibition, or both. Clin Neurophysiol 115:1239-1248. CrossRef Medline

Mink JW (2001) Basal ganglia dysfunction in Tourette's syndrome: a new hypothesis. Pediatr Neurol 25:190-198. CrossRef Medline

Montgomery EB Jr (2006) Effects of GPi stimulation on human thalamic neuronal activity. Clin Neurophysiol 117:2691-2702. CrossRef Medline

Montgomery EB Jr, Gale JT (2008) Mechanisms of action of deep brain stimulation (DBS). Neurosci Biobehav Rev 32:388-407. CrossRef Medline

Nambu A, Llinaś R (1994) Electrophysiology of globus pallidus neurons in vitro. J Neurophysiol 72:1127-1139. Medline

Parent A, Bouchard C, Smith Y (1984) The striatopallidal and striatonigral projections: two distinct fiber systems in primate. Brain Res 303:385-390. CrossRef Medline

Parent M, Lévesque M, Parent A (2001) Two types of projection neurons in the internal pallidum of primates: single-axon tracing and threedimensional reconstruction. J Comp Neurol 439:162-175. CrossRef Medline

Peterson BS (2001) Neuroimaging studies of Tourette syndrome: a decade of progress. Adv Neurol 85:179-196. Medline

Piedimonte F, Andreani JC, Piedimonte L, Graff P, Bacaro V, Micheli F, Vilela Filho O (2012) Behavioral and motor improvement after deep brain stimulation of the globus pallidus externus in a case of Tourette's syndrome. Neuromodulation 16:55-58. Medline

Ranck JB Jr (1975) Which elements are excited in electrical stimulation of mammalian central nervous system: a review. Brain Res 98:417-440. CrossRef Medline

Rodriguez-Oroz MC, et al. (2005) Bilateral deep brain stimulation in Parkinson's disease: a multicentre study with 4 years follow-up. Brain 128: 2240-2249. CrossRef Medline

Sato F, Lavallée P, Lévesque M, Parent A (2000a) Single-axon tracing study of neurons of the external segment of the globus pallidus in primate. J Comp Neurol 417:17-31. CrossRef Medline

Sato F, Parent M, Levesque M, Parent A (2000b) Axonal branching pattern of neurons of the subthalamic nucleus in primates. J Comp Neurol 424: 142-152. CrossRef Medline

Scarnati E, Di Loreto S, Proia A, Gallié G (1988) The functional role of the pedunculopontine nucleus in the regulation of the electrical activity of entopeduncular neurons in the rat. Arch Ital Biol 126:145-163. Medline 
Shahed J, Poysky J, Kenney C, Simpson R, Jankovic J (2007) GPi deep brain stimulation for Tourette syndrome improves tics and psychiatric comorbidities. Neurology 68:159-160. CrossRef Medline

Smith Y, Parent A (1986) Differential connections of caudate nucleus and putamen in the squirrel monkey (Saimiri sciureus). Neuroscience 18: 347-371. CrossRef Medline

Starr PA, Turner RS, Rau G, Lindsey N, Heath S, Volz M, Ostrem JL, Marks WJ Jr (2004) Microelectrode-guided implantation of deep brain stimulators into the globus pallidus internus for dystonia: techniques, electrode locations, and outcomes. Neurosurg Focus 17:E4. Medline

Stefani A, Fedele E, Galati S, Pepicelli O, Frasca S, Pierantozzi M, Peppe A, Brusa L, Orlacchio A, Hainsworth AH, Gattoni G, Stanzione P, Bernardi G, Raiteri M, Mazzone P (2005) Subthalamic stimulation activates internal pallidus: evidence from cGMP microdialysis in PD patients. Ann Neurol 57:448-452. CrossRef Medline

Tass PA, Majtanik M (2006) Long-term anti-kindling effects of desynchronizing brain stimulation: a theoretical study. Biol Cybern 94:58-66. CrossRef Medline

van der Linden C, Colle H, Vandewalle V, Alessi G, Rijckaert D, De Waele L (2002) Successful treatment of tics with bilateral internal pallidum (GPI) stimulation in a 27-year-old male patient with Gilles de la Tourette's syndrome. Mov Disord 17:S341.

Vandewalle V, van der Linden C, Groenewegen HJ, Caemaert J (1999) Stereotactic treatment of Gilles de la Tourette syndrome by high frequency stimulation of thalamus. Lancet 353:724. CrossRef Medline

Welter ML, Mallet L, Houeto JL, Karachi C, Czernecki V, Cornu P, Navarro S, Pidoux B, Dormont D, Bardinet E, Yelnik J, Damier P, Agid Y (2008) Internal pallidal and thalamic stimulation in patients with Tourette syndrome. Arch Neurol 65:952-957. CrossRef Medline

Welter ML, Grabli D, Vidailhet M (2010) Deep brain stimulation for hyperkinetics disorders: dystonia, tardive dyskinesia, and tics. Curr Opin Neurol 23:420-425. CrossRef Medline

Windels F, Bruet N, Poupard A, Urbain N, Chouvet G, Feuerstein C, Savasta M (2000) Effects of high frequency stimulation of subthalamic nucleus on extracellular glutamate and GABA in substantia nigra and globus pallidus in the normal rat. Eur J Neurosci 12:4141-4146. CrossRef Medline

Worbe Y, Baup N, Grabli D, Chaigneau M, Mounayar S, McCairn K, Féger J, Tremblay L (2009) Behavioral and movement disorders induced by local inhibitory dysfunction in primate striatum. Cereb Cortex 19: 1844-1856. CrossRef Medline 